\title{
Mutations and polymorphisms of Hirschsprung disease candidate genes in Thai patients
}

\author{
Surasak Sangkhathat $\cdot$ Takeshi Kusafuka \\ Piyawan Chengkriwate $\cdot$ Sakda Patrapinyokul $\cdot$ \\ Burapat Sangthong $\cdot$ Masahiro Fukuzawa
}

Received: 19 June 2006/ Accepted: 28 August 2006/Published online: 29 September 2006

(C) The Japan Society of Human Genetics and Springer 2006

\begin{abstract}
Mutation and polymorphism data for Hirschsprung disease (HSCR) varies among ethnic groups. Single nucleotide polymorphisms (SNP) of RET protooncogene (RET) were recently shown to be associated with the disease, and with disease severity, in different populations. In this study, comprehensive analysis of RET, GDNF, EDNRB, ET-3, and SOX-10 genes among sporadic HSCR in Thailand was conducted by standard PCR-SSCP, RFLP, and sequencing methods. Of 41 patients, 30 cases had rectosigmoid disease (RSD) and 11 cases were assigned to the long-segment disease (LSD) group. Four missense mutations of RET, S100M, R231H, T278N, and G533S, were identified in three patients. One novel missense mutation, V111Q, was detected in EDNRB. For ET-3, two novel missense mutations, D166E and C173R, occurred concomitantly in a patient. The incidence of missense mutation was significantly higher in our female HSCR patient than in the male counterpart. Statistical
\end{abstract}

S. Sangkhathat $(\bowtie) \cdot$ P. Chengkriwate

S. Patrapinyokul $\cdot$ B. Sangthong

Pediatric Surgery Unit, Department of Surgery,

Faculty of Medicine, Prince of Songkla University,

Hadyai, Songkhla 90110, Thailand

e-mail: surasak.sa@psu.ac.th

T. Kusafuka

Division of Pediatric Surgery,

Department of Surgery,

Nihon University School of Medicine,

30-1 Oyaguchikami-machi, Itabashi-ku,

Tokyo 173-8610, Japan

M. Fukuzawa $\cdot$ S. Sangkhathat

Department of Pediatric Surgery,

Osaka University Graduate School of Medicine,

2-2 Yamadaoka, Suita, Osaka 565-0871, Japan analysis of the SNPs revealed a significant difference between allele distribution of RET L769L in patients in the LSD and RSD groups. The predominant genotype construct of RET A45A/L769L in our HSCR was $\mathrm{GG} / \mathrm{GG}$, which is obviously different from results from all previous studies. The GG/GG genotype construct was associated with RSD and with males. The study also detected a variant allele of RET S836S which has never been reported in Asian cohorts.

Keywords Hirschsprung disease - RET - GDNF . EDNRB $\cdot$ ET-3 $\cdot$ SOX-10

\section{Introduction}

Hirschsprung disease (HSCR) is a congenital anomaly of the enteric nervous system which causes functional colonic obstruction. Pathologically, the disease is characterized by the absence of enteric ganglion cells in submucosal and myenteric nervous plexuses (Martuciello et al. 2000). The severity of HSCR is classified, on the basis of the extent of aganglionosis, into rectosigmoid disease (RSD) or long segment disease (LSD), according to whether the aganglionic portion is confined within the rectosigmoid colon or extends more proximally.

HSCR is a good and classic model for understanding the pathogenesis of multifactorial disease. During the past decade, at least eight genes associated with the disease have been identified (reviewed by Kusafuka and Puri 1997, 1998; Amiel and Lyonnet 2001; Puri and Shinkai 2004). Most candidate genes belong to two major signaling pathways which have essential roles in migration and maturation of an enteric neuroblast, 
RET transmembrane receptor system (RET, GDNF), and endothelin receptor system (EDNRB, ET-3). Not concentrating solely on missense mutations, recent studies have also explored a potential association between allelotypes of synonymous polymorphisms within RET and the occurrence of the disease (Borrego et al. 1999, 2000; Sancandi et al. 2003; GarciaBarcelo et al. 2003; Wu et al. 2005). Apart from these two pathways, heterozygous mutations of SOX-10, a member of Sry type HMG family of transcription factors, have been detected in patients with syndromic HSCR (Pingault et al. 1998).

Although the main disease susceptibility genes stated above and candidate single nucleotide polymorphisms (SNPs) of RET has been extensively investigated in HSCR patients from different ethnic groups, genotype data for South-East Asians remains unavailable. In this study, we performed a comprehensive genetic study for RET, GDNF, EDNRB, ET3 , and SOX-10 genes in sporadic HSCR patients in southern Thailand.

\section{Materials and methods}

Patients

Snap-frozen colon specimens from 41 consecutive cases of HSCR who were operated on at Songklanagarind Hospital, Thailand, from May 2003 to September 2005 were included in this study. Cases with family history of HSCR were excluded. Definitive diagnosis of aganglionosis was confirmed by histological examination. Patient demographic data were collected from hospital records using a standardized data-extraction form. Retrieval of clinical information and the genetic study were performed with permission from the $\mathrm{Re}$ search Ethic Committee of the Faculty of Medicine, Prince of Songkla University. We have had no opportunity to investigate the genotype in non-disease controls.

\section{Mutations analysis}

Genetic analysis was conducted at Osaka University, Japan. Mutation screening was performed by the polymerase chain reaction-single-stranded conformation polymorphism (PCR-SSCP) technique, which has been described elsewhere (Sangkhathat et al. 2005). Whole coding sequences of RET (20 exons), GDNF (2 exons), EDNRB (7 exons), and ET-3 (5 exons and promoter region) were amplified. Screening of SOX-10 mutations covered exon 3 to exon 5. With some exceptions, primer sequences used in this study followed previously published data (Kusafuka et al. 1997; Inoue et al. 1998; Sakai et al. 2000). Primer sequences used in our study can be provided on request.

Genotype study of RET SNP A45A and S904S in exons 2 and 15 was performed by restriction fragment length polymorphism (RFLP) analysis, using restriction enzyme Eco52I and RsaI (Toyobo, Japan).

Reference sequences and SNP information were obtained from the Ensemble Human Genome Browser; (http://www.ensembl.org/Homo_sapiens) and the National Center for Biotechnology Information (NCBI, http://www.ncbi.nlm.nih.gov).

\section{Statistical analysis}

Testing of the Hardy-Weinberg equilibrium (HWE) of allele distribution in each SNP with minor allele frequency larger than 0.01 was performed by chisquare-based methods, using the program Popgene (University of Alberta, Canada). The pairwise linkage disequilibrium (LD) test was performed by use of the same program. Results from the LD test were displayed as normalized linkage disequilibrium coefficients $\left(D^{\prime}\right)$, together with the $P$-value. Univariate analysis using chi-square test or Fisher's exact test, as appropriate, was performed for each SNP to determine the significance of differences between allele frequencies in the two length groups. Statistical analysis was performed using statistics software SPSS version 14.0 (SPSS, Chicago, IL, USA). Values are reported as raw numbers and percentages, where applicable. Categorical variables were compared using chi-square or Fisher's exact tests, as appropriate. The crude odds ratio with a 95\% confidence interval (CI) was also derived. Statistical significance was assumed for $P<0.05$, for all comparisons.

\section{Results}

Demographic data

Of the 41 cases investigated the male to female ratio was $34: 7$, or $4.9: 1$. There was no difference between sex ratios for $\operatorname{RSD}(5.0: 1)$ and $\operatorname{LSD}$ (4.5:1). With regard to the detailed extent of aganglionosis, in 30 patients $(73.2 \%)$ the lesion was confined to the rectosigmoid region, in nine cases $(22 \%)$ (including two cases with trisomy-21) the aganglionic colon extended to the transverse or descending colon, and two cases $(4.9 \%)$ had total colonic aganglionosis. With regard to racial grouping, 25 patients $(61.0 \%)$ were Chinese-Thai and 
16 were Malay-Thai. None of the subjects were biologically related. The incidence of missense mutation in female patients was higher than in male counterparts at a statistically significant level ( $P$-value: 0.027 ; odds ratio: $12.0,95 \%$ CI: $0.953,168.328)$.

\section{Sequence variants of RET and GDNF}

RET mutations were detected in five cases (Table 1). This figure does not include known SNPs with a frequency of minor allele at 0.02 or more (variants found in more than one allele in our HSCR population). Among seven points of sequence alteration, four were missense mutations. Three, S100M, T278N, and G533S, have not been reported previously. Interestingly, one infant with total colonic aganglionosis harbored two points of missense mutation on RET. The incidence of missense mutation of RET among Thai sporadic HSCR in our screening was, therefore, $3 / 41$ or $7.3 \%$. The study detected no aberrant band in fragment analysis of the GDNF amplicons.

Sequence variants of EDNRB, ET-3, and SOX-10

The study identified novel mutations of EDNRB in 3 of 41 cases analyzed, including one missense mutation at codon 111 and two silent mutations at codons 148 and 411, as summarized in Table 2. Excluding silent mutations which should be regarded as polymorphisms, the incidence of EDNRB mutations potentially related to the disease development was $1 / 41$ or $2.44 \%$
Screening of ET-3 detected four novel mutations in five cases, including two novel missense mutations (D166E and C173R) which occurred simultaneously in one case, one silent mutation in three cases, and one heterozygous $\mathrm{G}$ to $\mathrm{A}$ change in the promoter region (Table 2). The case that had a silent mutation at codon 411 of EDNRB also harbored a mutation at codon 142 of ET-3. The A142A polymorphism is reported here for the first time.

On the study of SOX-10, a deletion mutation involving 11 bases was found at position minus 58, upstream to exon 5. This case with the large deletion was the same as that harboring a heterozygous change at codon 148 of the EDNRB gene.

Allele distribution of RET, EDNRB, ET-10, and SOX-10 SNPs

SNP genotyping revealed no missing data. The allele distribution of the seven SNPs on the three genes is displayed in Table 3. Of the seven SNPs analyzed, distribution of the allele in six SNPs (RET A45A, A432A, L769L, S836S, EDNRB L277L, and ET-3 A142A) conformed with the HWE whereas SOX-10 $\mathrm{H} 309 \mathrm{H}$ deviated by a chi-square value of 7.60 ( $P$-value 0.004). Because of limited collection of samples from healthy individuals, we compared allele frequency between cases with different disease severity (LSD against RSD).

In univariate analysis, no SNP was found to have significantly different allele distribution between the two ethnic groups in our population (data not shown).

Table 1 Sequence variants of RET found in 41 cases

\begin{tabular}{|c|c|c|c|c|}
\hline RET exon & $\begin{array}{l}\text { Nucleotide } \\
\text { alteration }\end{array}$ & $\begin{array}{l}\text { Codon position and } \\
\text { amino acid change }\end{array}$ & $\begin{array}{l}\text { Sex/length of } \\
\text { aganglionosis group }\end{array}$ & Remarks \\
\hline Exon 2 & $\begin{array}{l}\mathrm{c} 135 \mathrm{G}>\mathrm{A} \\
\mathbf{c 2 9 9 G}>\mathbf{T}\end{array}$ & $\begin{array}{l}\text { A } 45 A \\
\text { S100M }\end{array}$ & $\begin{array}{l}\text { See Table } 4 \\
\text { F/RSD }\end{array}$ & \\
\hline Exon 3 & $\mathrm{c} 438 \mathrm{C}>\mathrm{T}^{\mathrm{a}}$ & $\mathrm{Y} 146 \mathrm{Y}$ & $\mathrm{M} / \mathrm{LSD}$ & \\
\hline Exon 4 & $\begin{array}{l}\mathbf{c 6 9 2} \mathbf{G}>\mathbf{A}^{\mathrm{b}} \\
\mathbf{c 8 3 3} \mathbf{C}>\mathbf{A}^{\mathrm{b}}\end{array}$ & $\begin{array}{l}\text { R231H } \\
\text { T278N }\end{array}$ & F/LSD & TCA \\
\hline Exon 7 & $\mathrm{c} 1296 \mathrm{G}>\mathrm{A}$ & A432A & See Table 4 & \\
\hline Exon 8 & c1597G $>A$ & G533S & M/LSD & Down syndrome ${ }^{c}$ \\
\hline Exon 13 & $\mathrm{c} 2307 \mathrm{~T}>\mathrm{G}$ & L769L & See Table 4 & \\
\hline Exon 14 & $\mathrm{c} 2508 \mathrm{C}>\mathrm{T}$ & S836S & M, F/LSD & Two cases ${ }^{\mathrm{a}}$ \\
\hline Exon 15 & $\mathrm{c} 2712 \mathrm{C}>\mathrm{G}$ & S904S & M/LSD & $\begin{array}{l}\text { TCA, ileal } \\
\text { involvement }\end{array}$ \\
\hline
\end{tabular}

Missense mutations are highlighted in bold

TCA - total colonic aganglionosis

a One case with S836S polymorphism also had synchronous Y146Y silent mutation

b These two missense mutations occurred in one infant with total colonic aganglionosis

c Confirmed trisomy 21 by G-band karyotyping 
Table 2 Sequence variants of EDNRB, ET-3, and SOX-10 found in 41 cases

Missense mutations are highlighted in bold

a One case with ET-3 A142A polymorphism also had synchronous EDNRB K411K mutation

b The two missense mutations occurred concomitantly in a male patient in the RSD group

Gene and exon Nucleotide alteration $\begin{aligned} & \text { Codon position and } \\ & \text { amino acid change }\end{aligned}$

Sex/length of

aganglionosis group

Remarks

\section{EDNRB}

Exon 1

Exon 1

Exon 4

Exon 5

Exon 7

ET-3

Promoter

Exon 3

Exon 3

\section{c332T $>$ A}

c $442 \mathrm{C}>\mathrm{T}$

c831A $>$ G

V111Q

L148L

c966C $>$ T

L277L

c1233A $>\mathrm{G}^{\mathrm{a}}$

A322A

K411K

F/RSD

$\mathrm{M} / \mathrm{RSD}$

See Table 4

$\mathrm{M} / \mathrm{RSD}$

$\mathrm{M} / \mathrm{RSD}$

Malrotation

SOX 10

Exon 5

c1(-125)G > A

Promoter

$\mathrm{c} 426 \mathrm{G}>\mathrm{A}^{\mathrm{a}}$

A142A

$\mathbf{c 4 9 8 C}>G^{b}$

D166E

$\mathbf{c 5 1 7 T}>\mathbf{G}^{\mathrm{b}}$

C173R

M/RSD

2M/RSD, 1M/LSD Three cases

M/RSD

Exon 5

c927C > T

$\mathrm{H} 309 \mathrm{H}$

c698(-58), del $11 \mathrm{nt}$

See Table 4

Intron 4-5

$\mathrm{M} / \mathrm{RSD}$
Table 3 Allele distribution of selected polymorphisms within RET, EDNRB, ET-3, and SOX-10, according to length of aganglionosis groups
$R S D$ - rectosigmoid disease, $L S D$-long segment disease

a Derived by use of the chisquare or Fisher's exact test as appropriate

\begin{tabular}{|c|c|c|c|c|c|c|}
\hline \multirow{2}{*}{$\begin{array}{l}\text { Gene, position, } \\
\text { and SNP code }\end{array}$} & \multirow{2}{*}{$\begin{array}{l}\text { Nucleotide } \\
\text { alteration }\end{array}$} & \multicolumn{3}{|c|}{ Allele frequency } & \multirow[t]{2}{*}{$P$-value ${ }^{\mathrm{a}}$} & \multirow{2}{*}{$\begin{array}{l}\text { Crude odds } \\
\text { ratio }(95 \% \\
\text { CI })\end{array}$} \\
\hline & & Total (N:82) & RSD (N:60) & LSD (N:22) & & \\
\hline \multicolumn{7}{|l|}{ RET } \\
\hline Exon 2 A45A & $\mathrm{c} 135 \mathrm{G}>\mathrm{A}$ & G: $64(0.78)$ & G: $50(0.83)$ & G: $14(0.64)$ & 0.056 & $\begin{array}{l}0.350(0.116 \\
1.054)\end{array}$ \\
\hline rs1800858 & & A: $18(0.22)$ & A: $10(0.17)$ & A: $8(0.36)$ & & \\
\hline Exon 7 A432A & $\mathrm{c} 1296 \mathrm{~A}>\mathrm{G}$ & A: $61(0.87)$ & A: $51(0.85)$ & A: $20(0.91)$ & 0.387 & $\begin{array}{l}1.765(0.350 \\
8.892)\end{array}$ \\
\hline rs1800860 & & G: 11 (0.13) & G: 9 (0.15) & G: 2 (0.09) & & \\
\hline Exon 13 L769L & $\mathrm{c} 2307 \mathrm{~T}>\mathrm{G}$ & G: $63(0.77)$ & G: $50(0.83)$ & G: $13(0.59)$ & 0.021 & $\begin{array}{l}3.462(1.166 \\
10.273)\end{array}$ \\
\hline rs1800861 & & $\mathrm{T}: 19(0.23)$ & $\mathrm{T}: 10(0.17)$ & $\mathrm{T}: 9(0.41)$ & & \\
\hline $\begin{array}{l}\text { Exon 14 S836S } \\
\text { rs1800862 }\end{array}$ & $\mathrm{c} 2508 \mathrm{C}>\mathrm{T}$ & $\begin{array}{l}\text { C: } 80(0.98) \\
\text { T: } 2(0.02)\end{array}$ & $\begin{array}{l}\text { C: } 60(1.00) \\
\text { T: } 0(0.00)\end{array}$ & $\begin{array}{l}\text { C: } 20(0.91) \\
\text { T: } 2(0.09)\end{array}$ & 0.070 & NA \\
\hline \multicolumn{7}{|l|}{ EDNRB } \\
\hline Exon 4 L277L & $\mathrm{c} 831 \mathrm{~A}>\mathrm{G}$ & A: $51(0.62)$ & A: $39(0.65)$ & A: $12(0.55)$ & 0.387 & $\begin{array}{l}1.548(0.573, \\
4.177)\end{array}$ \\
\hline $\begin{array}{l}\text { rs5351 } \\
\text { ET-3 }\end{array}$ & & G: 31 (0.38) & G: 21 (0.35) & G: $10(0.45)$ & & \\
\hline Exon 3 A142A & $\mathrm{c} 426 \mathrm{G}>\mathrm{A}$ & G: 79 (0.96) & G: 58 (0.97) & G: $21(0.95)$ & 0.613 & $\begin{array}{l}0.727(0.036 \\
44.73)\end{array}$ \\
\hline $\begin{array}{l}\text { (new) } \\
\text { SOX } 10\end{array}$ & & A: $3(0.04)$ & A: $2(0.03)$ & A: $1(0.05)$ & & \\
\hline Exon $5 \mathrm{H} 309 \mathrm{H}$ & $\mathrm{c} 927 \mathrm{C}>\mathrm{T}$ & C: 64 (0.78) & C: 46 (0.77) & C: $18(0.82)$ & 0.767 & $\begin{array}{l}0.730 \\
\quad(0.212,2.517)\end{array}$ \\
\hline rs139884 & & T: $18(0.22)$ & T: $14(0.23)$ & $\mathrm{T}: 4(0.18)$ & & \\
\hline
\end{tabular}

Table 4 Genotype distribution of RET polymorphisms A45A and L769L according to sex

\begin{tabular}{lllll}
\hline Sex & \multicolumn{2}{l}{ Genotype of RET: A45A/L769L $(\%)$} & \\
\cline { 2 - 5 } & GG/GG & GA/GT & AA/GG & Other remaining genotypes \\
\hline All $(n=41)$ & $23(56.1 \%)$ & $5(12.2 \%)$ & $1(2.4 \%)$ & $12(29.3 \%)$ \\
Male $(n=34)$ & $21(61.8 \%)$ & $1(2.9 \%)$ & $0(0 \%)$ & $12(35.3 \%)$ \\
Female $(n=7)$ & $2(28.6 \%)$ & $4(47.1 \%)$ & $1(14.3 \%)$ & $0(0 \%)$ \\
\hline
\end{tabular}

The distribution in the male and female patient groups was significantly different, as analyzed by the chi-square test (df 3$)$; chi-squared 22.4519, $P$-value 0.0001 
One of four RET SNPs (L769L in exon 13) had a statistically significantly increased minor allele frequency in the LSD group (Table 3). Interestingly, the $\mathrm{G}$ allele of RET A45A was statistically associated with the male sex ( $P$-value 0.048 , odds ratio: $3.484,95 \% \mathrm{CI}$ $0.823,13.909)$.

The pairwise LD test demonstrated that in our HSCR, RET A45A on exon 2 was in LD with RET L769L on exon $13\left(D^{\prime} 0.56, P\right.$-value $\left.<0.0001\right)$ and with S836S on exon 14 ( $D^{\prime} 0.80, P$-value 0.006$)$. In the same analysis we also discovered allele association between EDNRB L277L and ET-3 A142A ( $D^{\prime} 0.66, P$-value $0.020)$.

\section{Genotype distribution of RET SNPs in Thai HSCR}

We combined RET SNPs A45A and L769L for genotype analysis on the basis of previously published data showing disease association. To our surprise, the most common genotype in our HSCR patients was homozygous for $\mathrm{G}$ in both SNPs, which differed from the other Asian studies. This predominant genotype construct "GG/GG" was found significantly more frequently in the RSD group ( $70 \%$ in RSD, compared to $18 \%$ in LSD; $P$-value 0.04 , odds ratio: 0.095 and $95 \%$ CI: $0.017,0.532$ ). It should be noted that although GG/ GG was the predominant genotype in both ethnic groups in our studied population, there were some differences between Chinese-Thai (GG/GG frequency $68 \%$ ) and Malay-Thai (38\%). The variation was not significant when analyzed statistically.

Because differences between missense mutation rate and allele frequency of RETA45A were apparent in the different sexes, we were interested to look at the distribution of genotype by sex. It was found that genotype distributions in female patients significantly differed from those in the whole patient population and in male patients (Table 4). Instead of GG/GG, which contributed $61.8 \%$ in male cases, GA/GT accounted for $57.1 \%$ of our female cases.

\section{Discussion}

We report a comprehensive genetic study of HSCR patients in southern Thailand. Geographically, the region is situated in the middle part of the Malayu peninsula, between the mainland of Thailand and Malaysia. Previous study has suggested that the population in this region was an admixture of two ethnic factions, the Chinese-Thai extract from the Thai mainland and the Malay-Thai extract, which is predominantly Muslim (Fucharoen et al. 1989; Laosombat et al. 1992).
Even within the same racial group, incidences of mutation of HSCR-related genes differedaccording to the characteristics of the cases, the disease-causing mutation, and the method of screening. The mutation rate of RET among Asians is from 3.6 to $24 \%$ (Wu et al. 2005; Sakai et al. 2000; Tou et al. 2006; Garcia-Barcelo et al. 2004). Considering missense mutations in sporadic HSCR alone, figures reported are $7.1 \%$ for the Japanese (Sakai et al. 2000), 24\% for Hong Kong Chinese (Garcia-Barcelo et al. 2004), and $0 \%$ for Taiwan Chinese (Wu et al. 2005). Incidence of RET missense mutation at $7.3 \%$ was in agreement with results from with other series. One distinguishing feature that should be noticed in our patients was that six of seven mutations of RET belonged to the LSD group whereas mutations found in other genes were confined to cases with rectosigmoid extent. In agreement with other reports, cases harboring heterozygous mutation of EDNRB were mainly short segment HSCR who had unaffected parents or were asymptomatic (Amiel and Lyonnet 2001; Puri and Shinkai 2004; Tam and GarciaBarcelo 2004).

Reports from different geographic regions showed that some synonymous polymorphisms on RET had different allele distribution between HSCR cases and controls (Borrego et al. 2000; Sancandi et al. 2003; Garcia-Barcelo et al. 2003; Wu et al. 2005). Those studies also successfully identified a representative genotype or haplotype in their HSCR patients, and association between some SNPs and the severity of the disease. Statistical association between the SNPs A45A and L769L of RET and length of aganglionosis was observed for a cohort from Taiwan (Wu et al. 2005); this deviated from the previous series of Hong Kong Chinese, for whom analysis of RET A45A, A432A, and $\mathrm{L} 769 \mathrm{~L}$ revealed different allele frequency between length groups for RET A432A only (Garcia-Barcelo et al. 2003). Our current study confirmed association between allele distribution and the length of aganglionosis for the point RET L769L but rejected the point RET A45A, and A432A. Failure to demonstrate such association for RET A45A in our cases was probably a result of the inadequate sample size, because the $P$-value at 0.057 was close to the boundary of significance. Our data did, however, support a previous observation of an association between genotype of RET and severity of aganglionosis.

In the current series a variant allele of RET exon 14; S836S (c2508C > T) was detected that has been found in no other Asian series (Garcia-Barcelo et al. 2003; Wu et al. 2005; Sakai et al. 2000) and was detected in reduced frequency compared with healthy subjects in Italian HSCR (Griseri et al. 2000, 2002). In our HSCR, 
the minor allele in this polymorphism was found exclusively in patients of Malay-Thai extraction who had LSD. This ethnic subgroup is descended from the Malay Archipelago population, which may explain the genetic variation from other East Asian populations. Another major discrepancy between our data and other reports was at the haplotype frequency of the RET A45A and L769L, of which G-G was probably the predominant haplotype in our HSCR, in contrast with A-G in Chinese, Italian, and Spanish patients (Borrego et al. 2000; Sancandi et al. 2003; GarciaBarcelo et al. 2003; Wu et al. 2005). It has been shown in those population-based studies that the A allele of RET A45A has strong HSCR disease-association. Without a control panel, association of the $G$ allele of this SNP with HSCR could not be tested in our cases. We did, however, deduce from our findings that GG/ GG is the characteristic genotype construct for the RET A45A/L769L in HSCR patients in Southern Thailand and this genotype could be shown to have a significant association with short-segment phenotype and the male gender.

Sex is a known risk-modifying factor in HSCR phenotype development. A male individual has a greater risk or, in the other words, female patients may require stronger genetic alteration or more susceptible genetic background to develop HSCR phenotype. Our finding of higher mutation incidence in females was consistent with the observation in the Hong Kong cohort (GarciaBarcelo et al. 2004). Our study revealed the existence of different genotype between male and female HSCR for the first time. A allele in RET A45A was found in significantly higher frequency in female subjects compared with the whole group or with male patients. In females we also found the GA/GT, rather than GG/ $\mathrm{GG}$, genotype to be the predominant genotype for RET A45A/L769L. The significance of this distinct genotype pattern should be subjected to further study.

In summary, we performed a comprehensive genetic screening and SNP genotyping of HSCR-related genes in Thai sporadic cases. The study found missense mutations of RET, EDNRB, and ET-3 at rates comparable with those of previously studied cohorts in the Asian population. The study also revealed GG/GG as a predominant genotype construct of the RET A45A/ L769L which was associated with short-segment HSCR and the male gender.

Acknowledgments The study was partially supported by a grant-in-aid from the Ministry of Education, Sciences, Sports and Culture of Japan (Grant no.6591785). The authors wish to thank Kritsana Domdee, who established our biological banking system and Pornprot Limprasert, $\mathrm{MD}, \mathrm{PhD}$ for his suggestion in data analysis.

\section{References}

Amiel J, Lyonnet S (2001) Hirschsprung disease, associated syndromes, and genetics: a review. J Med Genet 38:729-739

Borrego S, Saez ME, Ruiz A, Gimm O, Lopez-Alonso M, Antinolo G, Eng C (1999) Specific polymorphisms in the RET proto-oncogene are over-represented in patients with Hirschsprung disease and may represent loci modifying phenotypic expression. J Med Genet 36:771-774

Borrego S, Ruiz A, Saez ME, Gimm O, Gao X, Lopez-Alonso M, Hernandez A, Wright FA, Antinolo G, Eng C (2000) RET genotypes comprising specific haplotypes of polymorphic variants predispose to isolated Hirschsprung disease. J Med Genet 37:572-578

Fucharoen S, Fucharoen G, Sriroongrueng W, Laosombat V, Jetsrisuparb A, Prasatkaew S, Tanpaichitr VS, Suvatte V, Tuchinda S, Fukumaki Y (1989) Molecular basis of betathalassemia in Thailand: analysis of beta-thalassemia mutations using the polymerase chain reaction. Hum Genet 84:41-46

Garcia-Barcelo MM, Sham MH, Lui VCH, Chen BLS, Song YQ, Lee WS, Yung SK, Romeo G, Tam PKH (2003) Chinese patients with sporadic Hirschsprung's disease are predominantly represented by a single RET haplotype. J Med Genet 40:122

Garcia-Barcelo M, Sham MH, Lee WS, Lui VC, Chen BL, Wong KK, Wong JS, Tam PK (2004) Highly recurrent RET mutations and novel mutations in genes of the receptor tyrosine kinase and endothelin receptor $\mathrm{B}$ pathways in Chinese patients with sporadic Hirschsprung disease. Clin Chem 50:93-100

Griseri P, Sancandi M, Patrone G, Bocciardi R, Hofstra R, Ravazzolo R, Devoto M, Romeo G, Ceccherini I (2000) A single-nucleotide polymorphic variant of the RET protooncogene is underrepresented in sporadic Hirschsprung disease. Eur J Hum Genet 8:721-724

Griseri P, Pesce B, Patrone G, Osinga J, Puppo F, Sancandi M, Hofstra R, Romeo G, Ravazzolo R, Devoto M, Ceccherini I (2002) A rare haplotype of the RET proto-oncogene is a risk-modifying allele in Hirschsprung disease. Am J Hum Genet 71:969-974

Inoue M, Hosoda K, Imura K, Kamata S, Fukuzawa M, Nakao K, Okada A (1998) Mutational analysis of the endothelin-B receptor gene in Japanese Hirschsprung's disease. J Pediatr Surg 33:1206-1208

Kusafuka T, Puri P (1997) The RET proto-oncogene: a challenge to understanding of disease pathogenesis. Pediatr Surg Int 12:11-18

Kusafuka T, Puri P (1998) Genetic aspects of Hirschsprung's disease. Semin Pediatr Surg 7:148-155

Kusafuka T, Wang Y, Puri P (1997) Mutation analysis of the RET, the endothelin-B receptor, and the endothelin- 3 genes in sporadic cases of Hirschsprung's disease. J Pediatr Surg 32:501-504

Laosombat V, Fucharoen SP, Panich V, Fucharoen G, Wongchanchailert M, Sriroongrueng W, Nopparatana C, Kenpitak K, Maipang M, Fukumaki Y (1992) Molecular basis of beta thalassemia in the south of Thailand. Am J Hematol 41:194-198

Martuciello G, Checcherini I, Lerone M, Jasonni V (2000) Pathogenesis of Hirschsprung's disease. J Pediatr Surg 35:1017-1025

Pingault V, Bonduran N, Kuhlbrodt K, Goerich DE, Prehu MO, Puliti A, Herbarth B, Hermans-Borgmeyer I, Legius E, Matthijs G, Amiel J, Lyonnet S, Ceccerini I, Romeo G, 
Smith JC, Read AP, Wegner M, Goosens M (1998) SOX10 mutations in patients with Waardenburg-Hirschsprung disease. Nat Genet 18:171-173

Puri P, Shinkai T (2004) Pathogenesis of Hirschsprung's disease and its variants: recent progress. Semin Pediatr Surg 13:18-24

Sakai T, Nirasawa Y, Itoh Y, Wakizaka A (2000) Japanese patients with sporadic Hirschsprung: mutation analysis of the receptor tyrosine kinase proto-oncogene, endothelin-B receptor, endothelin-3, glial cell line-derived neurotrophic factor and neurturin genes: a comparison with similar studies. Eur J Pediatr 159:160-167

Sancandi M, Griseri P, Pesce B, Patrone G, Puppo F, Lerone M, Martuciello G, Romeo G, Ravazzolo R, Devoto M, Ceccherini I (2003) Single nucleotide polymorphic alleles in the $5^{\prime}$ region of the RET proto-oncogene define a risk haplotype in Hirschsprung's disease. J Med Genet 40:714-718
Sangkhathat S, Chiengkriwate P, Kusafuka T, Patrapinyokul S, Fukuzawa M (2005) Novel mutation of endothelin-B receptor gene in Waardenburg-Hirschsprung disease. Pediatr Surg Int 21:960-963

Tam PKH, Garcia-Barcelo M (2004) Molecular genetics of Hirschsprung's disease. Semin Pediatr Surg 13:236-248

Tou JF, Li MJ, Guan T, Li JC, Zhu XK, Feng ZG (2006) Mutation of RET proto-oncogene in Hirschsprung's disease and intestinal neuronal dysplasia. World J Gastroenterol 12:1136-1139

Wu TT, Tsai TW, Chu CT, Lee ZF, Hung CM, Su CC, Li SY, Hsieh M, Li C (2005) Low RET mutation frequency and polymorphism analysis of the RET and EDNRB genes in patients with Hirschsprung disease in Taiwan. J Hum Genet 50:168-174 